\title{
Common mental health problems in historically disadvantaged urban and rural communities in South Africa: prevalence and risk factors
}

Received: 27 December 2006 / Accepted: 5 November 2007 / Published online: 5 December 2007

Abstract This paper reports on an epidemiological study of common mental health and substance abuse problems in a historically disadvantaged urban and rural community in South Africa. In the rural Limpopo Province of South Africa, and in a peri-urban township near Cape Town, self-report instruments were used in two random population samples and among respondents at primary care and traditional healer settings, to assess common mental health problems, substance abuse problems and associated problems in social functioning. A high prevalence of mental health and substance abuse problems was observed in both communities, with highest rates in the peri-urban township. Even higher prevalences were found among respondents at primary health care or traditional healers. The study shows that mental health and substance abuse problems constitute a considerable burden of disease among disadvantaged communities in South Africa. The study further underscores the integral role of traditional healers in the mental health care system.

Dr. J.M. Havenaar ( $₫)$

Dept. of Psychiatry

Vrije Universiteit Medical Centre Amsterdam

Valeriusplein 9

1075 BG, Amsterdam, The Netherlands

E-Mail: j.havenaar@ggzba.nl

M.I. Geerlings

Julius Center for Health Sciences and Primary Care

University Medical Center

Utrecht, The Netherlands

L. Vivian · B. Robertson

Dept. of Psychiatry and Mental Health

University of Cape Town

Cape Town, South Africa

M. Collinson

MRC/Wits University-Rural Public Health Research Unit

(Agin Court)

School of Public Health

University of Witwatersrand

Witwatersrand, South Africa
Key words epidemiology - mental health - substance abuse - primary care - traditional healers

\section{Introduction}

World-wide reports from the World Bank indicate that mental disorders and especially depression are among the most prevalent health problems, resulting in enormous losses in terms of human resources and economic potential $[1,2]$. Unfortunately, few studies have attempted to systematically assess mental health care needs in South Africa at the level of the community [3-5] and little information is available on risk factors associated with these problems [6]. Even fewer studies have assessed the prevalence of common mental health problems in primary care settings or at traditional healers [7-9]. An epidemiological study conducted by Bhagwanjee et al. [4] among rural African adults in Kwa-Zulu Natal, revealed an unexpectedly high prevalence of anxiety and depressive disorders amongst adults. Macleod and Masilela [10] on the basis of a qualitative evaluation of mental health care needs in the rural Agincourt sub-district indicate that mental health problems are wide spread, constituting a considerable burden to the community. Both authors conclude that primary health care services need to be improved to ensure that these disorders are adequately recognized and treated in this setting.

More epidemiological data are necessary to assist policy makers in their efforts to reform mental health care in South Africa. These include the reallocation of resources to achieve equity between urban and rural areas and different population groups, a reduction of the number of psychiatric hospital beds and a development of primary health care services so as to make these more accessible to all communities. Also there is a greater recognition of the role of traditional healers 
in the treatment of patients with psychiatric and psychosocial problems [11, 12].

In this paper, we aim to answer the following research questions:

1. What is the prevalence of common mental health problems, substance abuse, and related problems with social functioning among historically disadvantaged urban and rural populations in South Africa?

2. What is the prevalence of these mental health problems in primary care settings and among people using the services of traditional healers?

3. What risk factors are associated with prevalence of common mental health problems and substance abuse in the community?

\section{Material and methods}

\section{Design and study sites}

The study used a cross-sectional design and was conducted in the urban site of Khayelitsha, Western Cape and the rural site of the Agincourt sub-district, within the Bohlabelo (formerly Bushbuckridge) District of the Limpopo Province in the year 2000.

\section{Khayelitsha}

Khayelitsha is a sprawling peri-urban settlement on the outskirts of Cape Town with an estimated population of $1,000,000$. It is the largest African "township" in the Western Cape with a constant influx of people from rural and other areas of South Africa. Residents live in three different types of housing: formal housing in areas where services like piped water and water-borne or bucketsewerage are supplied; informal housing or shacks with the above services; and informal housing or shacks on unserviced land. A combination of very difficult living conditions, past experiences of political repression and violence, and the inaccessibility of mental heath services suggests that the residents of Khayelitsha are at a high risk of psychiatric disorder. The area where the research took place (Site C), is served by one community health centre. Outpatient psychiatric treatment is available in a community psychiatry clinic in a neighbouring area. There are no general or psychiatric hospitals in Khayelitsha.

\section{Agincourt}

Agincourt is situated adjacent to the border of the Kruger National Park, which in turn borders Mozambique. The Agincourt sub-district is essentially rural in character, with poor infrastructure and services, and yet it is densely populated with around 175 people living on each square kilometre. The sub-district was part of a former Bantustan 'homeland' that today could generally be considered impoverished when compared with the rest of the country. Many forms of temporary migration occur, including schooling, fostering, looking for work, working, and child support [13]. Within this area there is a community mental health care programme, a psychiatric out-patient support group [10], a district hospital, and a primary care clinic. The Agincourt Health and Population Unit, which is part of the Witwatersrand University rural facility, is running the longest established health and demographic surveillance system in southern Africa. It keeps a record of all births, deaths and migration in a circumscribed area and provides an excellent sampling frame for various public health studies. The demographic surveillance system was established in the early nineties of the previous century with the aim to support health service development at a time of government change and policy transition to a decentralised management and primary health care system [13].

\section{Setting and sampling procedures}

For the purpose of the present study, samples of adults aged 18-60 years were drawn from three levels of the community in both Khayelitsha and Agincourt: the general population, primary care settings and practices of several types of traditional healers active in the same areas. Differences between Khayelitsha and Agincourt and the two research teams prevented the adoption of identical research procedures. Our intention was not to compare the two sites, but to conduct separate but similar studies to investigate prevalence and risk factors for mental health problems in each area.

A sample size of two hundred respondents was decided upon for the community samples, eighty for the primary health care samples, and forty for the traditional healers.

\section{Khayelitsha}

1. The Site $\mathrm{C}$ district of Khayelitsha includes all three types of housing, and is broadly representative of Khayelitsha as a whole. Respondents were randomly selected by applying a random cluster-sampling frame applied to aerial photos of the township. Formal housing, and serviced and un-serviced informal housing areas were identified. Three areas of each type of housing were randomly selected to ensure a representative sample of housing in Site C. Interviewers were instructed to start at the corner of any street in each of the nine areas and approach every second dwelling, and, if no one was present, to approach the house before or the one after. In each house a list was made of eligible adults present, aged 18 years or older, and one of these was randomly selected using random number lists. The intention was to recruit 200 respondents by selecting at least twenty-two respondents in each of the nine areas. A total of 209 respondents were recruited.

2. A random sample of eighty consecutive patients attending the primary care clinic (community health centre) in Site C, Khayelitsha was obtained by interviewing 20 consecutive patients on different days of the week.

3. There are three types of traditional healers. Four diviners, two faith healers and two herbalists were recruited on a convenience basis, as there is no register of traditional healers. Forty-one consecutive clients were selected, 25 clients consulting diviners, 8 consulting faith healers, and 8 consulting herbalists.

Agincourt

1. In Agincourt, because of the high levels of mobility in the area, 300 adults aged 18-60 years were randomly selected from the demographic surveillance system data base, which covered all five village communities. Two hundred and twenty two interviews were completed.

2. In the primary care clinic respondents were drawn from the attendees of different clinic services. Sixty-six respondents were recruited.

3. In the Agincourt sample only diviners and faith healers were recruited. In total, 30 diviner clients and 15 faith healer clients were interviewed.

In Khayelitsha written consent and in Agincourt verbal informed consent was obtained from the respondent and suitable permissions were first obtained from the facility or the traditional healers where interviews were conducted.

\section{Measurements}

The interview schedule comprised the 20-item version of the Self Report Questionnaire (SRQ), developed by the WHO to screen for common mental health problems, particularly symptoms of anxiety and depression, at primary health care and community levels in developing countries, and has since then been suc- 
cessfully used for this purpose $[4,14]$. Because of the inherent limitations of instruments based on diagnostic categories, we decided that combining a dimensional scale such as the SRQ with a measurement of social functioning would give us more realistic data about mental health service needs than the use of instruments based on diagnostic categories. Although it has not been standardised locally, two earlier studies in South Africa reported moderate sensitivity and good specificity of the instrument in relation to caseness based on structured clinical interviews $[4,5]$. The schedule further included approximately 10 sociodemographic items, such as age, level of education, and marital status; a questionnaire screening for substance abuse and a measure of social functioning. The 11-item Substance Abuse Questionnaire, inquiring about alcohol and drug abuse, was adapted from a locally developed DSM IV-based questionnaire. The 32-item social impairment scale, adapted from a rating scale developed for schizophrenia, but using a different scoring system, inquired about problems in social functioning in relation to the reported mental health and substance abuse problems [15]. All measurements used past year as time frame. In addition, the interviewers rated the presence of visible poverty, based on whether the respondents had any food in the house for their next meal.

Before the start of the study the instruments were piloted in each site to check that the translations were clear in terms of language and culture [16] and were adjusted accordingly. Interviews in the Khayelitsha site were conducted by graduate anthropology students, who received intensive training by the research team. The Agincourt survey was conducted by experienced fieldworkers from the demographic surveillance system annual census after special training in the use of this particular interview schedule.

\section{Data analysis}

Means and standard deviations were computed for continuous variables, and frequency distributions were given for categorical variables across sites (Khayelitsha, Agincourt) as well as settings (community, primary care, traditional healer). Twelve-month prevalence rates and 95\% confidence intervals were calculated for common mental health problems, substance abuse, and related impairment of social functioning according to cut-off scores of 9 and higher on the SRQ, 1 and higher on the Substance Abuse Questionnaire (i.e. any substance abuse), and 8 and higher on the social impairment scale (i.e. impairment in 8 or more areas of social functioning). Logistic regression analysis was used to estimate the odds of having common mental health problems or substance abuse problems for each of the two sites separately. After stratification for site adjusted odds ratio's (AOR; adjusting for all other variables in the model) were calculated for sociodemographic and psychiatric risk factors risk associated with mental health or substance abuse problems. These risk factors were examined in the community sample only.

\section{Results}

In Khayelitsha, 330 people participated in the study, 209 from the general population, 80 consecutive attendees at a primary care clinic and 41 at traditional healers ( 8 at faith healers, 25 at diviners and 8 at herbalists). In Agincourt, 333 people participated, 222 from the community, 66 from primary care, and 45 from traditional healers ( 30 at diviners and 15 at faith healers).

Table 1 shows the distribution of risk factor variables for each site and setting. The mean age of respondents varied from 32 to 37 years in both sites. In Khayelitsha the sample consisted almost entirely of Xhosa speaking individuals (98.2\%), and more than half were women. Only $0.5 \%$ of the sample had no formal education. The rate of employment was $44.5 \%$ and visible poverty was noted by the interviewer in $32.1 \%$ of respondents. In the sample $24.3 \%$ of people were married, $38.3 \%$ living with a partner, and there was an average of 4.3 persons per household.

Table 1 Sociodemographic characteristics of study respondents

\begin{tabular}{|c|c|c|c|c|c|c|}
\hline & \multicolumn{3}{|c|}{ Khayelitsha $(N=330)$} & \multicolumn{3}{|c|}{ Agincourt $(N=333)$} \\
\hline & $\begin{array}{l}\text { Community } \\
N=209\end{array}$ & $\begin{array}{l}\text { Primary care } \\
N=80\end{array}$ & $\begin{array}{l}\text { Traditional healer } \\
N=41\end{array}$ & $\begin{array}{l}\text { Community } \\
N=222\end{array}$ & $\begin{array}{l}\text { Primary care } \\
N=66\end{array}$ & $\begin{array}{l}\text { Traditional healer } \\
N=45\end{array}$ \\
\hline Age & $31.9(9.5)$ & $36.4(10.3)$ & $37.7(9.0)$ & $32.8(12.4)$ & $34.2(11.4)$ & $37.5(11.8)$ \\
\hline \multicolumn{7}{|l|}{ Sex } \\
\hline Male & 40.7 & 50.0 & 48.8 & 30.2 & 36.3 & 31.1 \\
\hline Female & 59.3 & 50.0 & 51.2 & 69.8 & 63.6 & 68.9 \\
\hline \multicolumn{7}{|l|}{ Level of education } \\
\hline No education & 0.5 & 6.3 & 2.4 & 14.9 & 15.2 & 31.1 \\
\hline Primary & 15.9 & 17.7 & 29.3 & 24.4 & 40.9 & 42.2 \\
\hline Any secondary & 43.8 & 59.5 & 26.8 & 31.7 & 25.8 & 15.6 \\
\hline Completed secondary or tertiary & 39.9 & 16.5 & 41.5 & 29.0 & 18.2 & 11.1 \\
\hline \multicolumn{7}{|l|}{ Employment status } \\
\hline Employed & 44.5 & 40.4 & 61.0 & 17.6 & 13.8 & 22.2 \\
\hline Unemployed & 44.0 & 55.8 & 29.3 & 68.3 & 67.7 & 73.3 \\
\hline Student or pensioner & 11.5 & 3.8 & 9.8 & 14.0 & 18.5 & 4.4 \\
\hline Poverty present & 32.1 & 56.3 & 29.3 & 15.3 & 22.7 & 20.0 \\
\hline \multicolumn{7}{|l|}{ Marital status } \\
\hline Married & 24.3 & 30.0 & 29.3 & 41.5 & 53.8 & 48.9 \\
\hline Divorced or widowed & 8.3 & 12.5 & 17.1 & 12.4 & 13.8 & 24.4 \\
\hline Never married & 67.5 & 57.5 & 53.7 & 46.1 & 32.3 & 26.7 \\
\hline Living with partner & 38.3 & 46.3 & 58.5 & 49.1 & 57.6 & 55.6 \\
\hline Children & 58.9 & 67.5 & 70.7 & 68.9 & 69.7 & 82.2 \\
\hline$N$ persons in household & $4.3(1.9)$ & $3.8(1.6)$ & $3.4(1.3)$ & $7.0(2.9)$ & $7.2(3.1)$ & $7.1(3.9)$ \\
\hline
\end{tabular}


Table 2 Prevalence rates and 95\% confidence intervals using the Wilson method of mental health and substance abuse problems and social impairment at both sites

\begin{tabular}{|c|c|c|c|c|c|c|}
\hline & \multicolumn{3}{|c|}{ Khayelitsha $(N=330)$} & \multicolumn{3}{|c|}{ Agincourt $(N=333)$} \\
\hline & $\begin{array}{l}\text { Community } \\
N=209\end{array}$ & $\begin{array}{l}\text { Primary care } \\
N=80\end{array}$ & $\begin{array}{l}\text { Traditional healer } \\
N=41\end{array}$ & $\begin{array}{l}\text { Community } \\
N=222\end{array}$ & $\begin{array}{l}\text { Primary Care } \\
N=66\end{array}$ & $\begin{array}{l}\text { Traditional healer } \\
N=45\end{array}$ \\
\hline SRQ 9+, \% & $34.9(28.8-41.6)$ & 72.5 (61.9-81.1) & 82.9 (68.7-91.5) & $27.0(21.6-33.2)$ & $57.6(45.6-68.8)$ & $51.1(37.0-65.0)$ \\
\hline SA $1+, \%$ & $17.7(13.1-23.4)$ & $45.0(34.6-55.9)$ & $24.4(13.8-39.3)$ & $15.3(11.2-20.6)$ & $21.2(13.1-32.5)$ & $24.4(14.2-38.7)$ \\
\hline SI $8+, \%$ & $6.2(3.7-10.3)$ & $1.3(0.2-6.7)$ & $4.9(1.3-16.1)$ & $1.4(0.5-3.9)$ & $4.5(1.6-12.5)$ & $15.6(7.7-28.8)$ \\
\hline
\end{tabular}

SRQ 9+: A score of 9 or higher on the Self-report Questionnaire

SA 1+: A score of 1 or higher on the Substance Abuse Questionnaire

SI 8+: A score of 8 or higher on the social impairment scale

In Agincourt almost all respondents spoke Shangaan (96.4\%), two-thirds consisted of women, and $14.9 \%$ had no formal education. The rate of employment was $17.6 \%$, but visible poverty was noted in only $15.3 \%$ of respondents. In the sample $41.5 \%$ of people were married, $49.1 \%$ living with a partner, and there was an average of 7 persons per household.

Table 2 shows the prevalence and $95 \%$ confidence intervals of higher than cut-off score on the SRQ, the substance abuse questionnaire and the social impairment scale. In general, the symptoms scores in Khayelitsha were higher than in Agincourt. In Khayelitsha, more than one-third $(34.9 \%)$ of the community sample reported high levels of anxiety or depression symptoms on the SRQ. Among the respondents from primary care and traditional healer samples high SRQ rates were found among about three quarters of respondents (72.5 and 82.9\%, respectively). Substance abuse problems were also quite prevalent across the sub-samples at this site, and particularly in primary care, where almost half of the respondents (45\%) reported at least one alcohol or drug abuse related problem. Social impairment in relation to mental health problems or substance abuse was however not particularly prevalent.

In Agincourt, $27 \%$ of the community sample showed significant symptoms of depression, anxiety or other common mental health problems, while these symptoms were approximately twice as high in people attending primary care or traditional healer services. The prevalence of substance abuse problems was around half that of common mental health problems in all groups, but it was still considerable in all settings $(15.3 \%$ in the community and more than $20 \%$ in primary care and the traditional healer patients). Like in Khayelitsha substance abuse problems were most frequently reported among primary care attendees. In Agincourt problems with social functioning were reported most frequently by clients of traditional healers.

Table 3 shows the adjusted odds ratio's resulting from the multiple logistic regression analyses of the association between several risk factors and a high SRQ score and substance abuse problems in the community samples by site. The adjusted odds ratio's were calculated in the community samples only. The risk pattern for having a high score on the SRQ differed considerably by site. For the Khayelitsha sample, being female (AOR 2.85; 95\% CI 1.38-5.90), and being unemployed (AOR 2.70; 95\% CI 1.25-5.84) were associated with a higher risk of having mental health problems. For the Agincourt sample having no, or only primary education (AOR 3.75 ; 95\% CI 1.618.69), and having visible poverty as recorded by the interviewer (AOR 2.59; 95\% CI 1.12-5.98) were associated with an increased risk for these problems.

For substance abuse problems the following sociodemographic risk factors were found. Being female was a protective factor in both study sites (in Khayelitsha AOR 0.23; 95\% CI 0.11-0.67; in Agincourt AOR $0.08 ; 95 \%$ CI $0.03-0.24)$. Being divorced or widowed (AOR 6.30; 95\% CI 1.66-23.98) was associated with an increased risk of substance abuse problems for the Khayelitsha sample. In addition to these sociodemographic variables having a high SRQ score (AOR 2.31; 95\% CI 1.14-6.74) was associated with a higher risk of substance abuse problems for the Khayelitsha, but not the Agincourt sample.

\section{Discussion}

The purpose of this study was to assess the prevalence and risk factors of common mental health and substance abuse problems in a historically disadvantaged urban and rural area in South Africa, and to provide information about the presence of such problems among attendees of primary care and traditional healers. To our knowledge there is no other study in South Africa which has studied common mental health problems in these different settings, and in particular, there is no previous data about common mental health problems among traditional healer clients in this country. Also, no previous study has systematically investigated mental health problems in a historically disadvantaged urban and rural area, even though we acknowledge that the different sampling methods used to obtain the community samples do not allow a direct comparison between the two sites. The importance of the study further lies in the fact that the study takes an approach based on needs for care, using dimensional 
Table 3 Risk factors associated with mental health problems and substance abuse problems in two community samples

\begin{tabular}{|c|c|c|c|c|c|c|c|c|}
\hline & \multicolumn{4}{|c|}{ Khayelitsha } & \multicolumn{4}{|c|}{ Agincourt } \\
\hline & \multicolumn{2}{|c|}{ SRQ 9+ } & \multicolumn{2}{|c|}{ SA $1+$} & \multicolumn{2}{|c|}{ SRQ 9+ } & \multicolumn{2}{|c|}{ SA $1+$} \\
\hline & $A O R$ & $95 \% \mathrm{Cl}$ & $A O R$ & $95 \% \mathrm{Cl}$ & $A O R$ & $95 \% \mathrm{Cl}$ & $A O R$ & $95 \% \mathrm{Cl}$ \\
\hline \multicolumn{9}{|l|}{ Age group } \\
\hline $17-25$ year & 1 & & 1 & & 1 & & 1 & \\
\hline $26-35$ year & 0.64 & $0.28-1.47$ & 0.74 & $0.26-2.10$ & 0.54 & $0.20-1.50$ & 0.28 & $0.05-1.64$ \\
\hline $36-70$ year & 0.58 & $0.20-1.69$ & 0.60 & $0.15-2.32$ & 0.42 & $0.15-1.20$ & 2.79 & $0.66-11.76$ \\
\hline \multicolumn{9}{|l|}{ Gender } \\
\hline Male & 1 & & 1 & & 1 & & 1 & \\
\hline Female & 2.85 & $1.38-5.90$ & 0.27 & $0.11-0.67$ & 1.33 & $0.55-3.23$ & 0.08 & $0.03-0.24$ \\
\hline \multicolumn{9}{|l|}{ Educational level } \\
\hline Secondary or tertiary & 1 & & 1 & & 1 & & 1 & \\
\hline No or primary & 0.91 & $0.35-2.41$ & 1.77 & $0.61-5.14$ & 3.75 & $1.61-8.69$ & 1.05 & $0.31-3.54$ \\
\hline \multicolumn{9}{|l|}{ Employment status } \\
\hline Employed & 1 & & 1 & & 1 & & 1 & \\
\hline Unemployed & 2.70 & $1.25-5.84$ & 1.31 & $0.48-3.59$ & 1.08 & $0.45-2.57$ & 0.74 & $0.22-2.50$ \\
\hline Student/pensioner & 2.77 & $0.92-8.37$ & 1.38 & $0.33-5.80$ & 0.56 & $0.14-2.25$ & 1.46 & $0.30-6.99$ \\
\hline \multicolumn{9}{|l|}{ Marital status } \\
\hline Married & 1 & & 1 & & 1 & & 1 & \\
\hline Divorced/widowed & 0.81 & $0.22-3.07$ & 7.47 & $1.63-34.24$ & 1.22 & $0.46-3.26$ & 1.93 & $0.42-8.82$ \\
\hline Never married & 0.60 & $0.26-1.40$ & 1.30 & $0.37-4.54$ & 0.69 & $0.27-1.75$ & 0.98 & $0.22-4.31$ \\
\hline \multicolumn{9}{|l|}{ Has children } \\
\hline Yes & 1 & & 1 & & 1 & & 1 & \\
\hline No & 0.49 & $0.21-1.10$ & 1.37 & $0.50-3.78$ & 0.85 & $0.33-2.17$ & 2.71 & $0.74-9.95$ \\
\hline \multicolumn{9}{|l|}{ Poverty observed } \\
\hline No & 1 & & 1 & & 1 & & 1 & \\
\hline Yes & 0.66 & $0.31-1.43$ & 2.16 & $0.90-5.15$ & 2.59 & $1.12-5.98$ & 0.67 & $0.18-2.54$ \\
\hline \multicolumn{9}{|l|}{ SRQ score } \\
\hline$<9$ & - & & - & & 1 & & 1 & \\
\hline 9 or more & - & & - & & 2.72 & $1.14-6.53$ & 2.23 & $0.78-6.34$ \\
\hline
\end{tabular}

AOR: adjusted odds ratios, adjusted for all other variables in the table

SRQ 9+: A score of 9 or higher on the Self-report Questionnaire

SA 1+: A score of 1 or higher on the Substance Abuse questionnaire measurements combined with assessment of impairment, rather than relying on diagnoses.

The study demonstrates that common mental health problems and substance abuse problems are highly prevalent both in the peri-urban township of Khayelitsha and in the densely settled rural area of Agincourt, with roughly a third of the general population, and half to three quarters among attendees at primary care or traditional healer settings reporting symptom levels above the threshold value on the SRQ-20. Although previous studies in South Africa indicate that only $50 \%$ of individuals with such symptom levels may meet criteria for a psychiatric disorder $[4,5]$, the findings of this study suggest that many of these individuals nevertheless seek care from primary health care services or traditional healers.

More than $86 \%$ of primary care respondents across both sites scored above the threshold on either the SRQ or the substance abuse scale. These findings confirm the high prevalence of mental health problems among primary health care attendees reported by many other investigators [17]

The study further shows that the great majority of traditional healer clients scored above the threshold on either the SRQ or the substance abuse scale. Preliminary analyses of qualitative data collected in the traditional healer settings alongside those re- ported here, show that traditional healers were only occasionally consulted explicitly for mental health problems such as alcoholism or violent outbursts. Typical presenting problems included disturbing dreams, "fits", job loss, sores on legs, and issues relating to a son's initiation. Although the methodology of the study does not permit firmer conclusions to be drawn, the high prevalence of mental health problems among these clients suggests that, at another level, they may be seeking mental health care. Although there were clear differences in the type of treatment meted out by the three types of healers, a striking finding was that the same treatment, such as taking snuff, drinking herbal medicine, or sprinkling holy water, was frequently prescribed for different presenting problems, and that different treatments were prescribed for the same presenting problem, for instance job loss, or alcoholism. The traditional healer consultations will be described in more detail in a separate paper.

Traditional healers charged more than primary health care clinics. The somewhat higher educational and employment levels at the traditional healer setting in Khayelitsha, and the higher rates of poverty in primary care seem to suggest that financial motives may also be involved in choosing between settings in the township, but less clearly so in the rural area. 
Overall, respondents at both sites reported a relatively low prevalence of impairment in social functioning in relationship to the reported mental health problems. This should not be surprising as common mental health problems by definition are less impairing than serious mental illness, especially in non-referred samples of individuals. On the other hand, the high rates of help-seeking suggest that social functioning may be more impaired than our results indicate. Such a discrepancy could be related to problems with the validity of the instrument, due to lack of standardisation or cultural factors. It could also be argued that the instrument was inappropriate for common mental health problems. However, the instrument was used primarily to ensure comprehensive coverage of areas of social functioning applicable to all individuals, and not only those with schizophrenia.

The data show a profile of risk factors that differs considerably by site. Not surprisingly, the factors associated with having an increased risk for common mental health problems are similar to those generally reported in the literature $[18,19]$. However, it seems that in the peri-urban township unemployment and female gender are significantly more important, as is the presence of substance abuse problems, whereas in the rural environment these factors are not associated with an increased risk, but lower educational achievement and the presence of poverty are the key risk factors in that context. For substance abuse the protective effect of being female is confirmed for both sites, but marital status and the presence of common mental health problems are significant risk factors in the peri-urban township only. In the urban situation again poverty comes out as a significant predictor of substance abuse problems. No straightforward explanation for these differences can be given, especially in view of the different sampling methods used in the two sites. Perhaps these findings, practically all of which remain significant after correcting for the other risk factors in the model, reflect the greater social cohesion in the rural setting, which may mitigate the disadvantage of being female or marital status, whereas poverty and educational status are more important in this setting were the availability of jobs is much less than in the township.

A significant limitation of the study is that sampling procedures differed across sites, which precludes comparison of data. The decision to sample the next house when no one was present in the selected dwelling may have led to selection bias by over sampling of unemployed, domestically employed or ill people at this site. This may be a possible explanation for the high prevalence rates we found at the urban site. Another limitation of the study is that the instruments were not standardised for the populations sampled. Therefore, the findings reported in this paper are only indicative of the magnitude of the prevalence of mental health problems in these communities according to the cut-off points specified, and may not be generalised to other populations. Nevertheless, the study confirms the high rates of mental health problems reported in two earlier studies from rural communities $[4,5]$. The observed health care penalty associated with urban township living is in line with the literature from Western countries [18, 19]. In the general medical literature urbanisation is usually associated with a positive change in health conditions, as evidenced by rural versus urban child mortality differentials in African countries [20]. However, for mental health problems an opposite relationship is usually observed [19]. Also, emerging literature on developing world cities notes that contemporary cities bear the double burden of higher levels of infectious disease related epidemics, in addition to higher morbidity and mortality levels associated with non-infectious diseases [21]. In our study, this double burden is likely to apply also to the rural setting of Agincourt, with sharply rising infectious and non-infectious causes of death in rural settings [22]. This burden of ill physical health in both disadvantaged settings may be an important backdrop to the psychological symptoms experienced by these populations.

In conclusion, this study suggests that mental health and substance abuse problems may constitute a considerable burden of disease among disadvantaged communities in South Africa, and in particular in the peri-urban townships. Although the study did not formally investigate pathways to care, the data suggest that a significant proportion of affected individuals consult primary health care services, or traditional healers, or both, and that traditional healers are already an integral part of the South African mental health care system. However, we also found some indications of inequity of accessibility for this type of service. Considering the enormous burden on the primary care system of South Africa and other African countries, e.g. in dealing with epidemics of infectious and non-infectious diseases, cooperation between primary health care and traditional healers in the care of common mental health conditions may hold important opportunities, as well as caveats.

Further studies are needed, using standardised instruments, to confirm these findings, and to investigate treatment utilization rates and effectiveness of treatment for common mental health problems among both biomedical and traditional practitioners in under-resourced communities in South Africa.

Acknowledgements This study was supported by a grant from the South Africa Netherlands Programme for Alternatives in Development (SANPAD). The authors wish to acknowledge the contributions of T. Burmeister and O. Oloyede in the fieldwork procedures. 


\section{References}

1. World Bank (1993) World development report. Oxford University Press, Washington DC

2. WHO (1996) Investing in health and development. Report of the Ad Hoc Committee on health research relating to future intervention options. WHO, Geneva

3. Freeman M, de Beer C (1992) Viewing primary mental health care at time of social transition in South Africa. Int J Health Serv 22:339-348

4. Bhagwanjee A, Parekh A, Paruk Z, Petersen I, Subedar H (1998) Prevalence of minor psychiatric disorders in an adult African rural community in South Africa. Psychol Med 28:1137-1147

5. Rumble S, Swartz L, Parry C, Zwarenstein M (1996) Prevalence of psychiatric morbidity in the adult population of a rural South African village. Psychol Med 26:997-1007

6. Parry CDH (1996) A review of psychiatric epidemiology in Africa: strategies for improving validity when using instruments transculturally. Transcult Psychiatric Res Rev 33:173-178

7. Pillay AL, Kriel AJ (2006) Mental health problems in women attending district-level services in South Africa. Soc Sci Med 63:587-592

8. Strauss PR, Gagiano CA, Van Rensburg PHJJ, de Wet KJ Strauss HJ (1995) Identification of depression in a rural general practice. S Afr Med J 84:755-762

9. Thom RG, Zwi RM, Reinach SG (1993) The prevalence of psychiatric disorders at a primary care clinic in Soweto, Johannesburg. S Afr Med J 83:653-755

10. Macleod C, Masilela TC (1998) Feedback of research results: reflections from a community-based mental health programme. S Afr J Psychol 28:215-221

11. Gater R, de Almeida e Sousa B, Barrientos G Caraveo J, Chandrashekar CR, Dhadphale M, Goldberg D, al Kathiri AH, Mubbashar M, Silhan K, Thong D, Torres-Gonzales F, Sartorius N (2001) The pathways to psychiatric care: a cross-cultural study. Psychol Med 21:761-774
12. Patel V, Todd C, Winston M, Gwanzura F, Simunyu E, Acuda W, Mann A (1997) Common mental disorders in primary care in Harare, Zimbabwe: associations and risk factors. Br J Psychiatry 171:60-64

13. http://hermes.wits.ac.za/www/Health/PublicHealth/Agincourt/ (2006)

14. Harding TW, de Arango MV, Baltazar J Climent CE, Ibrahim HH, Ladrido-Ignacio L, Murthy RS, Wig NN (1980) Mental disorders in primary health care: a study of their frequency and diagnosis in four developing countries. Psychol Med 10:231241

15. Stevens BC (1972) Dependence of schizophrenic patients on elderly relatives. Psychol Med 2:17-32

16. Kortmann F (1990) Psychiatric case finding in Ethiopia: shortcomings of the Self Reporting Questionnaire. Cult Med Psychiatry 14:381-391

17. Wittchen HU, Holsboer F, Jacobi F (2001) Met and unmet needs in the management of depressive disorder in the community and primary care: the size and breadth of the problem. J Clin Psychiatry 62(Suppl 26):23-28

18. Eng PM, Kawachi I, Fitzmaurice G, Rimm EB (2005) Effects of marital transitions on changes in dietary and other health behaviours in US male health professionals. J Epidemiol Commun Health 59:56-62

19. Fryers T, Melzer D, Jenkins R (2003) Social inequalities and the common mental disorders: a systematic review of the evidence. Soc Psychiatry Psychiatr Epidemiol 38:229-237

20. Garenne M (2003) Migration, Urbanisation and Child Health in Africa: a global perspective. In "Africa on the move: African Migration and Urbanisation in Comparative Perspective". M. Tienda (ed) 2006. Wits University Press, Johannesburg

21. Montgomery MR, Stren R (2003) Cities transformed: demographic change and its implications in the developing world. National Academic Press, Washington DC

22. Kahn K, Garenne M, Tollman SM, Collinson MA (2007) Mortality trends in a new South Africa (Agincourt 1992-2003): hard to make a fresh start. Scand J Pub Health 35 (Suppl 69):26-34 